\title{
Model Pengukuran Kualitas Audit pada Kantor Akuntan Publik di Kota Medan : Pendekatan Partial Least Squares (PLS) - SEM Analisys
}

\author{
Novien Rialdy ${ }^{1)}$, M. Firza Alpi ${ }^{2}$, Nadia Ika Purnama ${ }^{3)}$, Januri ${ }^{4)}$ \\ ${ }^{1,2,3,4}$ Fakultas Ekonomi dan Bisnis, Universitas Muhammadiyah Sumatera Utara - Medan \\ *Email korespondensi: novienrialdy@umsu.ac.id
}

\begin{abstract}
This study aims to analyze the factors that affect the quality of the audit at the public accounting firm in Medan. This research is a basic research. The research was conducted in several public accounting firms $(K A P)$ in Medan City. The population in this study were all independent auditors who worked at the Public Accounting Firm (KAP) in Medan City, which were registered in the IAI Directory of the Public Accountants Compartment in 2018-2019, totaling 168 auditors. Sampling is done using probability techniques that provide equal opportunities for each member of the population to be elected. Because the number of the study population is small, all populations are sampled (census). The data used in this study are primary and secondary data. Primary data used in this study were obtained by distributing questionnaires to internal auditors who work at the Public Accounting Firm (KAP) in Medan City. The results showed that there was a significant effect of accountability on audit quality. There is a significant effect of competence on audit quality. There is a significant effect of independence on audit quality. There is a significant effect of professional ethics on audit quality. And the professional ethics moderation model is able to strengthen the influence of competence on audit quality.
\end{abstract}

Keywords: Competence, Independence, Accountability, Auditor Ethics, Audit Quality

Saran sitasi: Rialdy, N., Alpi, M. F., Purnama, N. I., \& Januri. (2021). Model Pengukuran Kualitas Audit pada Kantor Akuntan Publik di Kota Medan : Pendekatan Partial Least Squares (PLS) - SEM Analisys. Jurnal Akuntansi dan Pajak, 21 (2), 432-442. doi:http://dx.doi.org/10.29040/jap.v21i2.1514

DOI: http://dx.doi.org/10.29040/jap.v21i2.1514

\section{PENDAHULUAN}

Kualitas audit merupakan kemungkinan akan menemukan dan melaporkan pelanggaran dalam buku sistem akuntansi kliennya oleh auditor (DeAngelo, 1981). Penipuan yang dilakukan oleh auditor eksternal di Indonesia negara membuka cakrawala warga negara Indonesia tentang bagaimana entitas tersebut diperiksa membuat suap untuk mendapatkan hasil audit yang baik. Minat berbeda antara pebisnis dan manajemen membuat kualitas audit tidak mudah dilakukan. Manajemen perusahaan dan pemerintah membutuhkan jasa auditor eksternal sehingga penyajian akuntabilitas keuangan kepada pihak luar dapat dipercaya, sementara pihak luar membutuhkan layanan pihak ketiga untuk mendapatkan keyakinan bahwa penyajian laporan keuangan bisa dipercaya sebagai dasar dalam pengambilan keputusan oleh manajemen perusahaan (Mulyadi, 2014). Kualitas audit adalah setiap kemungkinan bahwa auditor selama proses diaudit kliennya bisa menemukan pelanggaran dalam sistem akuntansi klien dan dilaporkan dalam laporan keuangan yang diaudit, dimana auditor dalam melaksanakan tugasnya dipandu oleh standar audit dan kode etik yang diterima secara umum akuntan publik yang relevan (Usman, et al, 2014).

Standar audit yang diterima secara umum di Indonesia mengharuskan auditor untuk memiliki dan menerapkan kompetensi, pengalaman, independensi, hak perawatan profesional, integritas dan etika, ini digunakan sebagai dasar untuk mengukur kualitas kualitas pribadi auditor sehingga hasil auditnya berkualitas (Kertarajasa, et al, 2019).Hasil kualitas audit adalah sesuatu yang harus auditor capai dalam setiap proses audit. Hasil kualitas audit dibutuhkan oleh pihak yang berkepentingan seperti yang akan terjadi dapat diandalkan oleh pengguna sebagai dasar untuk mengambil keputusan. Sebagai hasil dari kualitas audit dapat membantu pembuat kebijakan dalam hal pemerintah, untuk membuat kebijakan dan 
peraturan untuk kesejahteraan masyarakat (Pritama, et al, 2017).

Kompetensi adalah pengetahuan secara keseluruhan berupa keterampilan dan kemampuan, sikap kerja dan atribut kepribadian yang dimiliki oleh seseorang (Dinata, 2006). Auditor yang tidak memiliki kompetensi cenderung bergantung pada orang lain dalam menyelesaikan tugas, karena sangat terbatas pengetahuannya. Sementara kompetensi dalam standar audit yang berlaku harus dimiliki oleh auditor. Auditor yang lebih kompeten semakin tinggi kualitas audit yang mereka berikan. Ini menunjukkan hubungan positif antara kompetensi dan kualitas audit yang dilakukan oleh auditor.

Selain faktor kompetensi dan pengalaman yang berpengaruh terhadap kualitas audit, independensi juga mempengaruhi auditor untuk memberikan kualitas audit. Independensi auditor merupakan dasar utama kepercayaan publik terhadap profesi eksternal auditor dan merupakan salah satu faktor terpenting untuk menilai kualitas layanan audit (Mulyadi, 2014). Oleh karena itu, untuk menghasilkan kualitas audit yang baik, independensi dari auditor sangat diperlukan dari auditor. Karena jika auditor tidak independen, laporan audit tidak menunjukkan realitas ekonomi. sehingga tidak bisa digunakan sebagai dasar pengambilan keputusan membuat. Faktor lain yang dapat meningkatkan kualitas audit adalah Due professional care. Karena Due professional care mengharuskan auditor untuk melakukan skeptisisme profesional, pertanyaan pikiran (Mulyadi, 2014). Dalam standar pengauditan, khususnya standar umum, disebutkan bahwa audit harus dilaksanakan oleh seorang atau lebih yang memiliki keahlian dan pelatihan teknis cukup sebagai auditor serta dalam pelaksanaan audit dan penyusunan laporannya auditor wajib menggunakan kemahiran profesionalnya dengan cermat dan seksama (due professional care).

Rasa tanggungjawab (akuntabilitas) yang dimiliki pemeriksa dalam menyelesaikan pekerjaan audit mempengaruhi kualitas audit. Pada profesi auditor, pasang surut kinerja auditor telah banyak memberikan dampak pada kondisi perekonomian suatu bangsa. Kemudian Citra buruk yang menjadi sorotan tajam karena kinerja auditor dinilai belum optimal. Beberapa kejadian yang mempunyai dampak negatif terhadap auditor itu mendorong profesi auditor agar semakin meningkatkan hasil pekerjaannya khususnya mengenai aspek moralitas. Sebagai ilustrasi adalah bangkrutnya ENRON dan terkena sanksi beberapa Kantor Akuntan Publik (KAP) di Indonesia oleh Departemen Keuangan karena tidak memenuhi standar dan etika Profesi. Ada banyak penelitian psikologi sosial yang membuktikan adanya hubungan dan pengaruh akuntabilitas seseorang terhadap kualitas pekerjaan. Menurut (Messier Jr. \& Quilliam, 1992) mengungkapkan bahwa akuntabilitas yang dimiliki auditor dapat meningkatkan proses kognitif auditor dalam mengambil keputusan. Selanjutnya (Tetlock \& Kim, 1987) juga mengkaji mengenai permasalahan akuntabilitas auditor dalam menyelesaikan sebuah pekerjaan. Berikutnya (Cloyd, 1997) meneliti interaksi akuntabilitas dengan pengetahuan untuk menentukan kualitas hasil kerja pada auditor yang menangani masalah perpajakan. Berdasarkan penelitian itu terbukti bahwa akuntabilitas dapat meningkatkan kualitas hasil kerja auditor.

Berdasarkan hasil penelitian terdahulu yang menunjukkan hasil yang berbeda terkait dengan faktorfaktor yang berpengaruh terhadap kualitas audit, maka peneliti termotivasi untuk melakukan penelitian kembali. Peneliti mengembangkan penelitian dari (Samsi, et al, 2013) dan (Saripudin, et al, 2012). Perbedaan penelitian ini dengan penelitian sebelumnya terletak penggunaan variabel due professional care sebagai variable intervening dan etika auditor sebagai variabel moderasi dan yang mungkin akan mempengaruhi secara kuat atau lemah hubungan antara kompetensi, independensi, akuntabilitas dan kualitas audit.

\section{METODE PENELITIAN}

Dalam penelitian ini penulis menggunakan pendekatan kuantitatif. Pendekatan kuantitatif digunakan karena data yang akan digunakan untuk menganalisis pengaruh antar variabel dinyatakan dengan angka atau skala numerik. Penelitian ini akan menjelaskan hubungan mempengaruhi dan dipengaruhi dari variabel-variabel yang akan diteliti. Penelitian dilakukan di beberapa Kantor Akuntan Publik (KAP) yang ada di Kota Medan. Populasi adalah keseluruhan obyek penelitian yang ingin diteliti (Arikunto, 2013). Populasi dalam penelitian ini adalah seluruh auditor independen yang bekerja pada Kantor Akuntan Publik (KAP) di Kota Medan, yang terdaftar di Direktori IAI Kompartemen Akuntan Publik tahun 2018-2019.Penelitian ini menggunakan sampel pada Kantor Akuntan Publik (KAP) di Kota Medan sebagai langkah awal untuk pembentukan 
model pengukuran kualitas audit.Populasi penelitian adalah pada Kantor Akuntan Publik (KAP) di Kota Medan yang berjumlah 168 orang auditor. Penarikan sampel dilakukan dengan teknik probability yang memberikan peluang yang sama bagi setiap anggota populasi untuk terpilih. Oleh karena jumlah populasi penelitian sedikit, maka semua populasi dijadikan sampel (sensus).Data yang dipergunakan dalam penelitian ini adalah data primer. Data primer yang dipergunakan dalam penelitian ini diperoleh dengan cara penyebaran kuesioner kepada auditor yang bekerja di Kantor Akuntan Publik (KAP) di Kota Medan, yang terdaftar di Direktori IAI Kompartemen Akuntan Publik tahun 2018-2019. Teknik analisis data yang sesuai dengan penulisan ini adalah analisis deskriptif dan analisis kuantitatif dengan menggunakan SEM-PLS.

\section{HASIL DAN PEMBAHASAN}

\subsection{Hasil Penelitian}

\section{Evaluasi Model Pengukuran}

Evaluasi terhadap model pengukuran indikator meliputi pemerikasaan individual item reliability, internal consistency atau composite reliability, average variance extracted, dan discriminant validity.Ketiga pengukuran pertama dikelompokan dalam convergent validity.

\section{a. Convergent Validity}

Convergent validity terdiri dari tiga pengujian yaitu reliability item (validitas tiap indikator), composite reability, dan average variance extracted (AVE). Convergent validity digunakan untuk mengukur seberapa besar indikator yang ada dapat menerangkan dimensi.Artinya semakin besar convergent validity maka semakin besar kemampuan dimensi tersebut dalam menerapkan variabel latennya.

\section{1) Reliability Item}

Item reliabilitas atau biasa kita sebut dengan validitas indikator. Pengujian terhadap reability item (validitas indikator) dapat dilihat dari nilai loading factor (standardized loading). Nilai loading faktor ini merupakan besarnya korelasi antara antara setiap indikator dan konstraknya. Nilai loading factor diatas 0,7 dapat dikatakan ideal, artinya bahwa indikator tersebut dapat dikatakan valid sebagai indikator untuk mengukur konstrak. Meskipun demikian, nilai standardized loading factor diatas 0,5 dapat diterima. Sedangkan nilai standardized loading factor dibawah 0,5 dapat dikeluarkan dari model
Chin (1998). Berikut adalah nilai reability item yang dapat dilihat pada kolom standardized loading:

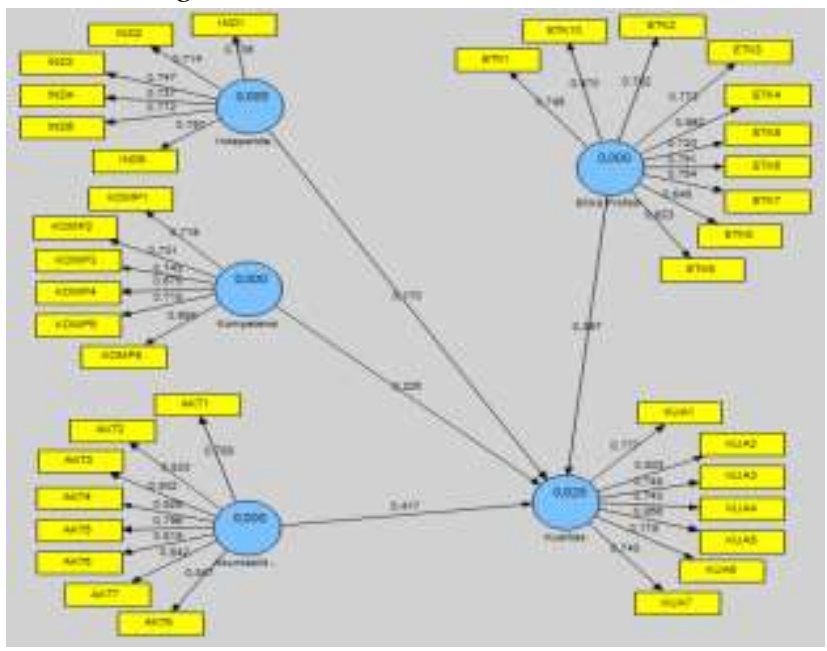

Gambar 1.Standardized Loading Factor Inner dan Outer Model

Dari gambar di atas dapat dilihat bahwa seluruh loading bernilai lebih dari 0,5 sehingga tidak perlu disisihkan. Dengan demikian, tiap indikator telah valid untuk menjelaskan masingmasing laten variabelnya yaitu independensi, kompetensi, akuntabilitas, etika profesi, dan kualitas audit.

Selain menunjukkan validitas item dari masing-masing indikator, loading factor juga menunjukkan besarnya kontribusi tiap indikator pada faktornya. Untuk independensi, indikator yang memiliki loading paling besar adalah IND5. Sedangkan untuk kompetensi, loading factor terbesar yaitu KOMP3. Untuk indikator pada akuntabilitas, loading factor terbesar yaitu AKT8. Indikator pada etika profesi, loading factor terbesar yaitu ETK6. Indikator pada kualitas audit, loading factor terbesar yaitu KUA2.

\section{2) Composite Reliability}

Statistik yang digunakan dalam composite reliability atau reabilitas konstrak adalah cronbach's alpha dan D.G rho (PCA). Nilai cronbach's alpha dan D.G rho (PCA) diatas 7,0 menunjukan konstrak memiliki reabilitas atau keterandalan yang tinggi sebagai alat ukur. Nilai batas 0,7 keatas berarti dapat diterima dan diatas 0,8 dan 0,9 berarti sangat memuaskan. 
Jurnal Akuntansi dan Pajak, 21 (02), 2021, 435

Tabel 1.

Hasil Composite Reliability

\begin{tabular}{cc}
\hline & Composite Reliability \\
\hline Akuntabilitas & 0.942 \\
\hline Etika Profesi & 0.913 \\
\hline Independensi & 0.881 \\
\hline Kompetensi & 0.860 \\
\hline Kualitas & 0.915 \\
\hline
\end{tabular}

Sumber : Hasil Pengolahan Data 2020

Berdasarkan tabel di atas menunjukan bahwa nilai composite reliability untuk independensi sebesar 0,942; kompetensi sebesar 0,913; akuntabilitas sebesar 0,881. Sementara untuk etika profesi dan kualitas audit sebesar 0,860 dan 0,915 . Kelima laten memperoleh nilai composite reliability diatas 0,7 sehingga dapat dikatakan seluruh faktor memiliki reabilitas atau keterandalan yang baik sebagai alat ukur.

3) Average Variance Extracted (AVE)

Average Variance Extracted (AVE) menggambarkan besaran variance yang mampu dijelaskan oleh item-item dibandingkan dengan varian yang disebabkan oleh error pengukuran. Standarnya adalah bila nilai AVE diatas 0,5 maka dapat dikatakan bahwa konstrak memiliki convergent validity yang baik. Artinya variabel laten dapat menjelaskan rata-rata lebih dari setengah variance dari indikator-indikatornya.

Tabel 2.

Hasil Average Variance Extracted (AVE)

\begin{tabular}{ll}
\hline & AVE \\
\hline Akuntabilitas & 0.672 \\
\hline Etika Profesi & 0.514 \\
\hline Independensi & 0.554 \\
\hline Kompetensi & 0.507 \\
\hline Kualitas & 0.608 \\
\hline
\end{tabular}

Sumber : Hasil Pengolahan Data 2020

Berdasarkan tabel di atas menunjukan bahwa nilai AVE untuk independensi sebesar 0,672; kompetensi sebesar 0,514; akuntabilitas sebesar 0,554. Sementara untuk etika profesi dan kualitas audit sebesar 0,507 dan 0,608. Kelima variabel memiliki AVE yang berada diatas 0,5 sehingga konstrak memiliki convergent validity yang baik dimana variabel laten dapat menjelaskan rata-rata lebih dari setengah variance dari indikator-indikatornya.

\section{b. Discriminant Validity}

Pemeriksaan discriminant validity dari model pengukuran reflektif yang dinilai berdasarkan cross loading dan membandingkan antara nilai AVE dengan kuadrat korelasi antarkonstrak. Ukuran cross loading adalah adalah membandingkan korelasi indikator dengan konstraknya dan konstrak dari blok lain. Discriminant validity yang baik akan mampu menjelaskan variabel indikatornya lebih tinggi dibandingkan dengan menjelaskan varian dari indikator konstrak yang lain. Berikut adalah nilai discriminant validity untuk masing-masing indikator.

Tabel 3. Discriminant Validity

\begin{tabular}{|cccccc}
\hline & $\begin{array}{c}\text { Akunta } \\
\text { bilitas }\end{array}$ & $\begin{array}{c}\text { Ptika } \\
\text { Profesi }\end{array}$ & $\begin{array}{c}\text { Indense } \\
\text { ndeni }\end{array}$ & Kompsi & Kual \\
itas \\
\hline AKT1 & $\mathbf{0 . 7 8 8}$ & 0.577 & 0.489 & 0.453 & 0.665 \\
\hline AKT2 & $\mathbf{0 . 8 3 3}$ & 0.649 & 0.540 & 0.499 & 0.702 \\
\hline AKT3 & $\mathbf{0 . 8 0 2}$ & 0.598 & 0.520 & 0.371 & 0.673 \\
\hline AKT4 & $\mathbf{0 . 8 2 8}$ & 0.607 & 0.439 & 0.384 & 0.697 \\
\hline AKT5 & $\mathbf{0 . 7 9 6}$ & 0.627 & 0.517 & 0.458 & 0.698 \\
\hline AKT6 & $\mathbf{0 . 8 1 9}$ & 0.563 & 0.503 & 0.425 & 0.681 \\
\hline AKT7 & $\mathbf{0 . 8 4 2}$ & 0.635 & 0.529 & 0.406 & 0.712 \\
\hline AKT8 & $\mathbf{0 . 8 4 7}$ & 0.597 & 0.502 & 0.446 & 0.664 \\
\hline ETK1 & 0.553 & $\mathbf{0 . 7 4 5}$ & 0.444 & 0.377 & 0.562 \\
\hline ETK10 & 0.522 & $\mathbf{0 . 6 7 0}$ & 0.331 & 0.343 & 0.543 \\
\hline ETK2 & 0.571 & $\mathbf{0 . 7 6 2}$ & 0.384 & 0.423 & 0.609 \\
\hline ETK3 & 0.546 & $\mathbf{0 . 7 7 3}$ & 0.326 & 0.360 & 0.573 \\
\hline ETK4 & 0.491 & $\mathbf{0 . 6 6 2}$ & 0.284 & 0.425 & 0.539 \\
\hline ETK5 & 0.538 & $\mathbf{0 . 7 2 0}$ & 0.398 & 0.401 & 0.574 \\
\hline ETK6 & 0.579 & $\mathbf{0 . 7 9 1}$ & 0.393 & 0.412 & 0.609 \\
\hline ETK7 & 0.566 & $\mathbf{0 . 7 5 4}$ & 0.335 & 0.356 & 0.575 \\
\hline ETK8 & 0.528 & $\mathbf{0 . 6 4 6}$ & 0.384 & 0.348 & 0.545 \\
\hline ETK9 & 0.380 & $\mathbf{0 . 6 2 3}$ & 0.226 & 0.233 & 0.401 \\
\hline IND1 & 0.395 & 0.297 & $\mathbf{0 . 7 3 6}$ & 0.437 & 0.472 \\
\hline IND2 & 0.458 & 0.349 & $\mathbf{0 . 7 1 4}$ & 0.397 & 0.510 \\
\hline IND3 & 0.467 & 0.292 & $\mathbf{0 . 7 4 7}$ & 0.409 & 0.471 \\
\hline IND4 & 0.452 & 0.431 & $\mathbf{0 . 7 3 7}$ & 0.441 & 0.520 \\
\hline IND5 & 0.493 & 0.374 & $\mathbf{0 . 7 7 2}$ & 0.419 & 0.532 \\
\hline IND6 & 0.481 & 0.441 & $\mathbf{0 . 7 5 7}$ & 0.516 & 0.570 \\
\hline KOMP1 & 0.392 & 0.433 & 0.460 & $\mathbf{0 . 7 1 6}$ & 0.523 \\
\hline KOMP2 & 0.394 & 0.361 & 0.430 & $\mathbf{0 . 7 3 1}$ & 0.500 \\
\hline KOMP3 & 0.351 & 0.390 & 0.404 & $\mathbf{0 . 7 4 3}$ & 0.481 \\
\hline KOMP4 & 0.254 & 0.273 & 0.374 & $\mathbf{0 . 6 7 5}$ & 0.391 \\
\hline KOMP5 & 0.439 & 0.357 & 0.431 & $\mathbf{0 . 7 1 8}$ & 0.510 \\
\hline KOMP6 & 0.385 & 0.380 & 0.406 & $\mathbf{0 . 6 8 8}$ & 0.493 \\
\hline KUA1 & 0.683 & 0.652 & 0.547 & 0.552 & $\mathbf{0 . 7 7 7}$ \\
\hline KUA2 & 0.663 & 0.605 & 0.571 & 0.592 & $\mathbf{0 . 8 0 3}$ \\
\hline KUA3 & 0.570 & 0.525 & 0.520 & 0.570 & $\mathbf{0 . 7 4 8}$ \\
\hline KUA4 & 0.653 & 0.622 & 0.458 & 0.490 & $\mathbf{0 . 7 4 3}$ \\
\hline KUA5 & 0.708 & 0.658 & 0.631 & 0.553 & $\mathbf{0 . 8 5 6}$ \\
\hline KUA6 & 0.649 & 0.557 & 0.513 & 0.510 & $\mathbf{0 . 7 7 8}$ \\
\hline KUA7 & 0.639 & 0.613 & 0.521 & 0.455 & $\mathbf{0 . 7 4 3}$ \\
\hline
\end{tabular}

Sumber : Hasil Pengolahan Data (2020) 
Berdasarkan tabel di atas menunjukan bahwa nilai discriminant validity atau loading factor untuk AKT1 adalah 0,788.Korelasi indikator AKT1 lebih tinggi padaakuntabilitas dibandingkan pada kompetensi, yaitu sebesar 0,453; terlebih pada independensi $(0,489)$, dan pada etika profesi sebesar 0,577 serta pada kualitas audit $(0,665)$. Korelasi indikator EKT1 lebih tinggi padaetika profesi (sebesar 0,745 ) dibandingkan pada akuntabilitas, yaitu sebesar 0,553 ; terlebih pada kompetensi $(0,377)$ dan pada independensi sebesar 0,444 serta pada kualitas audit $(0,562)$, demikian seterusnya. Semua nilai loading factor untuk tiap variabel memiliki korelasi yang lebih tinggi dengan variabelnya dibandingkan dengan variabel lainnya. Demikian pula dengan indikator indikator tiap variabelnya. Ini menunjukkan bahwa penempatan indikator pada tiap variabelnya telah tepat.

\section{Evaluasi Model Struktural}

Ada beberapa tahap dalam mengevaluasi model struktural.Pertama adalah melihat signifikansi pengaruh antara konstrak.Hal ini dapat dilihat dari koefisien jalur (path coefficient) yang menggambarkan kekuatan hubungan antar konstrak.

\section{a. Path Coeffecient}

Melihat signifikansi pengaruh antara konstrak dapat dilihat dari koefisien jalur (path coefficient). Tanda dalam path coefficient harus sesuai dengan teori yang dihipotesiskan, untuk menilai signifikansi path coefficient dapat dilihat dari t test (critical ratio) yang diperoleh dari proses bootstrapping (resampling method). Berikut hasil pengujian $\mathrm{t}$ terhadai innes dan outer model.

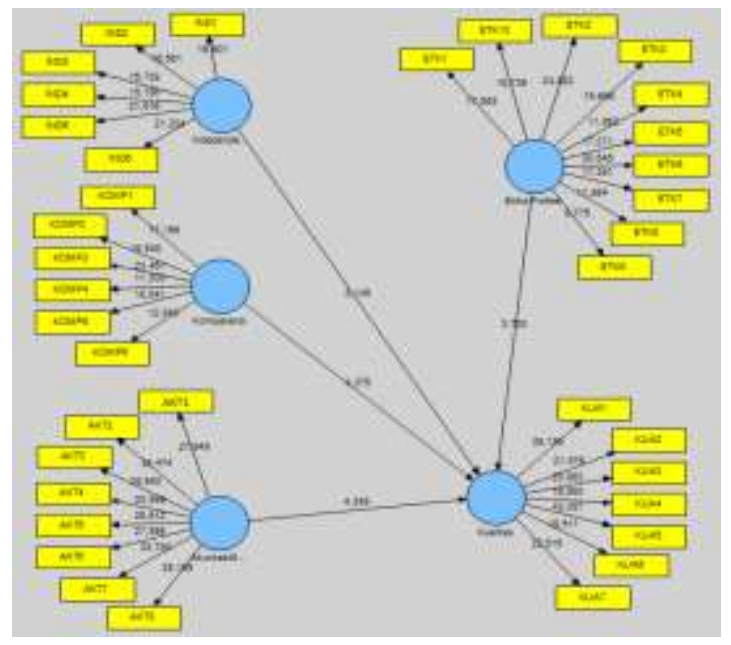

Gambar 2.T-Value Inner dan Outer Model

Uji t yang dilakukan merupakan hasil uji t dari perhitungan secara bootsttrap. Hasil uji t pada gambar di atas selanjutnya akan dibandingkan dengan nilai $t$ tabel.

Tabel 4.Hasil Path Coefficient Pengaruh Langsung

\begin{tabular}{lccccccc}
\hline & $\begin{array}{c}\text { Original } \\
\text { Sample (O) }\end{array}$ & $\begin{array}{c}\text { Sample } \\
\text { Mean (M) }\end{array}$ & $\begin{array}{c}\text { Standard Deviation } \\
\text { (STDEV) }\end{array}$ & $\begin{array}{c}\text { Standard Error } \\
\text { (STERR) }\end{array}$ & $\begin{array}{c}\text { T Statistics } \\
\text { (|O/STERR|) }\end{array}$ & $\begin{array}{c}\text { T } \\
\text { tabel }\end{array}$ \\
\hline Akuntabilitas -> Kualitas & 0.417 & 0.408 & 0.095 & 0.095 & 4.399 & 1.976 \\
\hline Etika Profesi -> Kualitas & 0.267 & 0.262 & 0.071 & 0.071 & 3.753 & 1.976 \\
\hline Independensi -> Kualitas & 0.170 & 0.183 & 0.079 & 0.079 & 2.149 & 1.976 \\
\hline Kompetensi -> Kualitas & 0.226 & 0.229 & 0.052 & 0.052 & 4.375 & 1.976 \\
\hline
\end{tabular}

Sumber : Hasil Pengolahan Data 2020

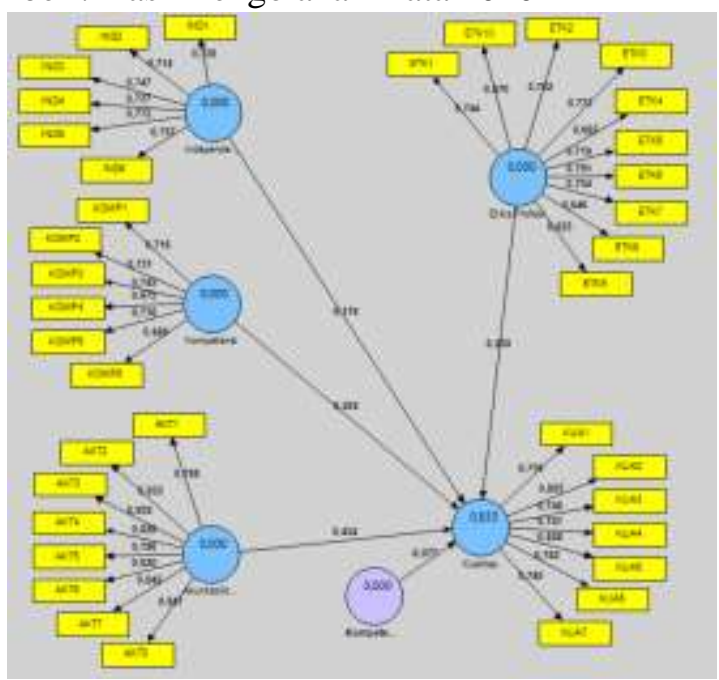

Gambar 3.

Pengaruh Variabel Etika Profesi sebagai Variabel

Moderator pada Pengaruh Kompetensi terhadap Kualitas Audit

Kriteria pengujian adalah tolak Ho jika t hitung > $\mathrm{t}$ tabel. Dari tabel $\mathrm{t}$ didapat nilai tabel untuk $\alpha=0,05$ dan $\mathrm{dk}=\mathrm{n}-2=150-2=148$ sehingga didapat $\mathrm{t}$ tabel sebesar 1,976. Dari tabel di atas, dapat dilihat bahwa : 1) Nilai $t$ statistic untuk akuntabilitas terhadap kualitas audit sebesar 4,399. Jika dibandingkan dengan nilai $\mathrm{t}$ tabel, maka t hitung $(4,399)<\mathrm{t}$ tabel $(1,976)$ sehingga Ho diterima. Dengan demikian dapat disimpulkanterdapat pengaruh yang signifikan dari akuntabilitas terhadap kualitas audit.Besarnya pengaruh akuntabilitas terhadap kualitas audit sebesar 0,417. Koefisien jalur yang bernilai positif menunjukkan semakin baik akuntabilitas maka semakin baik pula kualitas audit.

2) Nilai t statistic untuk kompetensi terhadap kualitas audit sebesar 4,375. Jika dibandingkan dengan 
Jurnal Akuntansi dan Pajak, 21 (02), 2021, 437

nilai $\mathrm{t}$ tabel, maka t hitung $(4,375)>\mathrm{t}$ tabel $(1,976)$ sehingga Ho ditolak. Dengan demikian dapat disimpulkan terdapat pengaruh yang signifikan dari kompetensi terhadap kualitas audit.Besarnya pengaruh kompetensi terhadap kualitas audit sebesar 0,226 . Koefisien jalur yang bernilai positif menunjukkan semakin baik kompetensi maka semakin baik pula kualitas audit.

3) Nilai t statistic untuk independensi terhadap kualitas audit sebesar 2,149. Jika dibandingkan dengan nilai t tabel, maka t hitung $(2,814970)>t$ tabel $(1,976)$ sehingga Ho ditolak. Dengan demikian dapat disimpulkan terdapat pengaruh yang signifikan dari independensi terhadap kualitas audit.Besarnya pengaruh independensi terhadap kualitas audit sebesar 0,170. Koefisien jalur yang bernilai positif menunjukkan semakin baik independensi maka semakin baik pula kualitas audit.

4) Nilai t statistic untuk etika profesi terhadap kualitas audit sebesar 3,753. Jika dibandingkan dengan nilai $\mathrm{t}$ tabel, maka $\mathrm{t}$ hitung $(3,753)>\mathrm{t}$ tabel $(1,976)$ sehingga Ho ditolak. Dengan demikian dapat disimpulkan terdapat pengaruh yang signifikan dari etika profesi terhadap kualitas audit.Besarnya pengaruh etika profesi terhadap kualitas audit sebesar 0,267 . Koefisien jalur yang bernilai positif menunjukkan semakin baik etika profesi maka semakin baik pula kualitas audit.

Tabel 5.Hasil Path Coefficient Pengaruh Adanya Variabel Moderasi

\begin{tabular}{cc}
\hline Original & $\begin{array}{c}\text { Standardized Loading } \\
\text { Sample (O) }\end{array}$ \\
$\begin{array}{c}\text { Factor dengan Mderasi } \\
\text { Etika Profesi }\end{array}$ \\
\hline
\end{tabular}

\section{Kompetensi ->}

$0.226 \quad 0.434$

Kualitas

Sumber : Hasil Pengolahan Data 2020

Hasil moderasi variabel etika profesi pada pengaruh kompetensi terhadap kualitas audit menunjukkan bahwa standardized loading factor atau path koefisien dengan adanya moderasi lebih besar, yaitu sebesar 0,434 dibandingkan dengan tanpa moderasi $(0,226)$. Ini menunjukkan bahwa model moderasi etika profesi mampu memperkuat pengaruh kompetensi terhadap kualitas audit.

b. Mengevaluasi $\mathbf{R}^{2}$

Berdasarkan nilai $\mathrm{R}^{2}$ diketahui bahwa variabelvariabel yang mempengaruhi etika profesi seperti independensi, kompetensi, akuntabilitas, dan etika profesi bersama-sama berpengaruh sebesar 0,829
$(82,9 \%)$, sedangkan sisanya $17,1 \%$ dari konstrak lainnya.

Tabel 6.Hasil $\mathbf{R}^{2}$

\begin{tabular}{lc}
\hline & R Square \\
\hline Kualitas Audit & 0.829 \\
\hline
\end{tabular}

Sumber : Hasil Pengolahan Data 2020

\section{c. Goodness Of Fit}

Untuk memvalidasi model secara keseluruhan, maka digunakan goodness of fit (GoF) yang diperkenalkan oleh Tenenhaus, et al (2004). GoF index ini merupakan ukuran tunggal yang digunakan untuk memvalidasi performa gabungan antara model pengukuran dan model structural. Nilai GoF ini diperoleh dari average communalities index dikalikan dengan nilai $\mathrm{R}^{2}$ model. Berikut adalah hasil perhitungan goodness of fit model :

Tabel 7.

Hasil Average Communalities Index

\begin{tabular}{|ccc|}
\hline & AVE & R Square \\
\hline Akuntabilitas & 0.672 & \\
\hline Etika Profesi & 0.514 & \\
\hline Independensi & 0.554 & \\
\hline Kompetensi & 0.507 & \\
\hline Kualitas & 0.608 & 0.829 \\
\hline Kompetensi & 0.571 & 0.829 \\
\hline Kualitas & \multicolumn{2}{|c|}{0.688} \\
\hline
\end{tabular}

Berdasarkan Tabel di atashasil rata-rata communalities adalah 0,571. Nilai ini selanjutnya dikalikan dengan $\mathrm{R}^{2}$ dan diakarkan. Hasil perhitungan menunjukan bahwa nilai GoF sebesar 0,688 lebih dari 0,36 sehingga dikategorikan sebagai $\mathrm{GoF}$ besar, artinya bahwa model sangat baik (memiliki kemampuan yang tinggi) dalam menjelaskan data empiris.

\subsection{Pembahasan}

\section{Pengaruh Akutabilitas terhadap Kualitas Audit}

Berdasarkan hasil pengolahan data diperoleh nilai $\mathrm{t}$ statistic untuk akuntabilitasterhadap kualitas audit sebesar 4,399. Jika dibandingkan dengan nilai t tabel, maka t hitung $(4,399)<\mathrm{t}$ tabel $(1,976)$ sehingga Ho diterima. Dengan demikian dapat disimpulkanterdapat pengaruh yang signifikan dari akuntabilitas terhadap kualitas audit.Besarnya pengaruh akuntabilitas terhadap kualitas audit sebesar 0,417. Koefisien jalur yang bernilai positif menunjukkan semakin baik akuntabilitas maka semakin baik pula kualitas audit. Hasil penelitian 
Singgih dan Bawono (2010) mengatakan bahwa akuntabilitas berpengaruh secara parsial terhadap kualitas audit. Akuntabilitas merupakan perwujudan kewajiban seseorang atau unit organisasi untuk mempertanggungjawabkan pengelolaan sumber daya dan pelaksanaan kebijakan yang dipercayakan kepadanya dalam rangka pencapaian tujuan yang telah ditetapkan. Begitu juga hasil penelitian yang dilakukan Mardisar (2007), Singgih dan Icuk (2010), dan juga Badjuri (2011) bahwa meningkatnya akuntabilitas Auditor akan berpengaruh terhadap peningkatan kualitas audit.

\section{Pengaruh Kompetensi terhadap Kualitas Audit}

Berdasarkan hasil pengolahan data diperoleh nilai $\mathrm{t}$ statistic untuk kompetensi terhadap kualitas audit sebesar 4,375. Jika dibandingkan dengan nilai t tabel, maka t hitung $(4,375)>t$ tabel $(1,976)$ sehingga Ho ditolak. Dengan demikian dapat disimpulkan terdapat pengaruh yang signifikan dari kompetensi terhadap kualitas audit.Besarnya pengaruh kompetensi terhadap kualitas audit sebesar 0,226. Koefisien jalur yang bernilai positif menunjukkan semakin baik kompetensi maka semakin baik pula kualitas audit.

Hal ini berarti, semakin tinggi kompetensi auditor, maka kualitas audit akan semakin baik. Dengan demikian, kualitas audit yang baik akan tercapai apabila auditor memiliki kompetensi yang tinggi. Auditor sebagai ujung tombak pelaksanaan tugas audit harus meningkatkan pengetahuannya agar penerapan pengetahuan dapat maksimal dan tentunya akan sejalan dengan semakin bertambahnya pengalaman yang dimiliki (Alim et al., 2007). Hasil penelitian ini sesuai dengan hasil penelitian yang dilakukan (Castellani, 2008) dan (Lufriansyah, 2017), bahwa terdapat pengaruh kompetensi terhadap kualitas audit. Kharismatuti \& Hadiprajitno, (2012), dalam penelitiannya menunjukkan bahwa kompetensi berpengaruh positif terhadap kualitas audit. Penelitian ini didukung oleh (Tjun, et al, 2012), dan (Ningsih \& Yaniartha, 2013). Penelitian yang mendukung juga dilakukan oleh (Arisanti, et al, 2013); (Kurnia et al., 2014), (Triarini \& Latrini, 2016). Ini diperkuat oleh hasil penelitian yang dilakukan oleh (Halim, et al, 2014); (Octavia \& Widodo, 2015); (Furiady \& Kurnia, 2015); (Pandoyo, 2016) dan (Zahmatkesh \& Rezazadeh, 2017) yang membuktikan bahwa terdapat pengaruh kompetensi terhadap kualitas auditor.

\section{Pengaruh Independensi terhadap Kualitas Audit}

Berdasarkan hasil pengolahan data diketahui bahwa nilai $\mathrm{t}$ statistic untuk independensi terhadap kualitas audit sebesar 2,149. Jika dibandingkan dengan nilai $t$ tabel, maka thitung $(2,814970)>t$ tabel $(1,976)$ sehingga Ho ditolak. Dengan demikian dapat disimpulkan terdapat pengaruh yang signifikan dari independensi terhadap kualitas audit.Besarnya pengaruh independensi terhadap kualitas audit sebesar 0,170. Koefisien jalur yang bernilai positif menunjukkan semakin baik independensi maka semakin baik pula kualitas audit.

Hasil penelitian (Lufriansyah, 2017) mebuktikan bahwa Independensi berpengaruh signifikan terhadap kualitas audit. Beberapa penelitian yang dialakukan diantaranya adalah penelitian (Alim et al., 2007) menunjukkan bahwa independensi memiliki pengaruh yang signifikan terhadap kualitas audit. Demikian pula penelitian (Ningsih \& Yaniartha, 2013), (Agusti \& Pertiwi, 2013), (Prasetyo \& Utama, 2015);

(Dewi \& Budiartha, 2015); (Rialdy, et al, 2020) dan (Made \& Aryanto, 2016) yang menunjukkan independensi memiliki pengaruh terhadap kualitas audit. Penelitian ini didukung oleh hasil penelitian yang dilakukan oleh (Halim et al., 2014), (Octavia \& Widodo, 2015), (Dewi \& Budiartha, 2015); (Pandoyo, 2016); (Pitaloka \& Widanaputra, 2016); (Rahayu \& Suryono, 2016) dan (Ariningsih \& Mertha, 2017) yang hasil penelitian mengungkapkan bahwa independensi mempengaruhi kualitas audit.

\section{Pengaruh Etika Profesi terhadap Kualitas Audit}

Berdasarkan hasil pengolahan data diperoleh nilai $\mathrm{t}$ statistic untuk etika profesi terhadap kualitas audit sebesar 3,753. Jika dibandingkan dengan nilai $t$ tabel, maka thitung $(3,753)>t$ tabel $(1,976)$ sehingga Ho ditolak. Dengan demikian dapat disimpulkan terdapat pengaruh yang signifikan dari etika profesi terhadap kualitas audit.Besarnya pengaruh etika profesi terhadap kualitas audit sebesar 0,267. Koefisien jalur yang bernilai positif menunjukkan semakin baik etika profesi maka semakin baik pula kualitas audit.

Hasil penelitian ini didukung oleh penelitian yang dilakukan oleh Sari (2011) yang menyatakan bahwa etika profesi memiliki pengaruh yang signifikan terhadap kualitas audit. Hasil penelitian ini mengindikasi bahwa semakin baik etika profesi yang di terapkan di Kantor Akuntan Publik di Kota Medan dalam pelaksanaan audit maka kualitas audit yang dihasilkan akan semakin baik. Begitu juga hasil 
penelitian yang dilakukan Suraida (2005) yang menyimpulkan bahwa etika profesi mempunyai pengaruh terhadap pemberian opini audit. Penelitian (Alim dkk, 2007) meneliti pengaruh etika profesi terhadap kualitas audit, hasil penelitiannya ini etika profesi tidak mempunyai pengaruh secara signifikan terhadap kualitas auditor.

\section{Pengaruh Kompetensi terhadap Kualitas Audit Dimoderasi Etika Profesi}

Hasil moderasi variabel etika profesi pada pengaruh kompetensi terhadap kualitas audit menunjukkan bahwa standardized loading factor atau path koefisien dengan adanya moderasi lebih besar, yaitu sebesar 0,434 dibandingkan dengan tanpa moderasi $(0,226)$. Ini menunjukkan bahwa model moderasi etika profesi mampu memperkuat pengaruh kompetensi terhadap kualitas audit.

Hasil penelitian ini berhasil membuktikan bahwa adanya kesadaran akan etika auditor yang harus diterapkan oleh auditor dalam bekerja akan menambah kompetensi seorang auditor dalam melakukan pekerjaanya, sehingga akan menghasilkan suatu kualitas audit yang berkualitas baik. Kualitas audit yang baik dapat dipengaruhi oleh kompetensi seorang auditor (Arens, 2008). Hasil penelitian ini sejalan dengan penelitian yang dilakukan oleh Wardhani \& Astika (2018) yang menyimpulkan bahwa etika auditor memperkuat pengaruh kompetensi pada kualitas audit.

\section{KESIMPULAN}

Hasil penelitian menunjukkan bahwa terdapat pengaruh yang signifikan dari akuntabilitas terhadap kualitas audit pada Kantor Akuntan Publik (KAP) di Kota Medan.Terdapat pengaruh yang signifikan dari kompetensi terhadap kualitas audit pada Kantor Akuntan Publik (KAP) di Kota Medan.Terdapat pengaruh yang signifikan dari independensi terhadap kualitas audit pada Kantor Akuntan Publik (KAP) di Kota Medan.Terdapat pengaruh yang signifikan dari etika profesi terhadap kualitas audit pada Kantor Akuntan Publik (KAP) di Kota Medan.Dan model moderasi etika profesi mampu memperkuat pengaruh kompetensi terhadap kualitas audit pada Kantor Akuntan Publik (KAP) di Kota Medan.

Berdasarkan hasil penelitian, analisis, serta kesimpulan, maka saran yang dapat diberikan adalah seorang auditor semestinya bekerja sesuai dengan etika yang berlaku serta memperhatikan faktor-faktor penting agar menghasilkan kualitas audit yang berkualitas. Bagi peneliti lain diharapkan agar mengamati faktor-faktor yang mempengaruhi kualitas audit pada populasi yang berbeda serta dapat menambah jumlah variabel independen dan mengganti variabel moderasi guna mengetahui variabel-variabel lain yang dapat memperkuat atau memperlemah variabel dependen. Bagi penelitian selanjutanya diharapkan agar menambah jumlah sampel dan memperluas lokasi pengambilan sampel yang tidak hanya di wilayah Kota Medan, selanjutnya sebaiknya melakukan sebuah penelitian dengan menggunakan metode wawancara langsung untuk mengumpulkan data penelitian agar dapat mengurangi adanya kelemahan dan bagi penelitian selanjutnya diharapkan agar dapat melengkapi data dengan melakukan observasi yang lebih mendalam.

\section{REFERENSI}

Agusti, R., \& Pertiwi, N. P. (2013). Pengaruh Kompetensi, Independensi Dan Profesionalisme Terhadap Kualitas Audit (Studi Empiris Pada Kantor Akuntan Publik Se-Sumatera). Jurnal Ekonomi, 21(3), 1-13.

Alim, M., Hapsari, T., \& Purwanti, L. (2007). Pengaruh Kompetensi Dan Independensi Terhadap Kualitas Audit Dengan Etika Auditor Sebagai Variabel Moderasi. Simposium Nasional Akuntansi X (pp. 1-26).

Arens, A. A., Elder, R. J., Beasley, M. S., \& Hogan, C. E. (2014). Auditing and. Assurance Services: An Integrated Approach. Singapore: Pearson.

Arif, B., \& Iskandar, M. (2002). Akuntansi Pemerintahan. Jakarta: Erlangga.

Arikunto, S. (2013). Prosedur Penelitian: Suatu Pendekatan Praktik. Jakarta: Rineka Cipta.

Ariningsih, P. S., \& Mertha, I. M. (2017). Pengaruh Independensi, Tekanan Anggaran Waktu, Risiko Audit, Dan Gender Pada Kualitas Audit. EJurnal Akuntansi Universitas Udayana, 18(2), 1545-1574.

Arisanti, D., Puspa, D. F., \& Herawati, H. (2013). Pengaruh Independensi, Pengalaman Kerja, Due Professional Care, Akuntabilitas dan Kompetensi terhadap Kualitas Audit. Jurnal Fakultas Ekonomi Universitas Bung Hatta, 2(1), 1-12.

Bernardin, H. J., \& Russel, J. E. . (2010). Human Resource Management. New York: McGraw Hill.

Boynton, W. C., Johnson, R. N., \& Kell, W. G. (2002). Modern Auditing (7th ed.). Jakarta: Erlangga. 
Carolita, M. K., \& Rahardjo, S. N. (2012). Pengaruh Pengalaman Kerja, Independensi, Objektifitas, Integritas, Kompetensi, Dan Komitmen Organisasi Terhadap Kualitas Hasil Audit (Studi pada Kantor Akuntan Publik di emarang). Diponegoro Journal of Accounting, 1(2), 1-11.

Castellani, J. (2008). Kompetensi dan Independensi Auditor Pengaruhnya pada Kualitas Audit. Jurnal Trikonomika, 7(2).

Chadegani, A. A. (2011). Review of Studies on Audit Quality. International Conference on Humanities Society and Culture. Singapore.

Cloyd, C. B. (1997). Performance in Reseach Task: The Joint Effect of Knowledge and Accountability. The Accounting Review, 72(1), 111-131.

DeAngelo, L. E. (1981). Auditor independence, 'low balling', and disclosure regulation. Journal of Accounting and Economics, 3(2), 113-127.

Dewi, D. A. C., \& Budiartha, I. K. (2015). Pengaruh Kompetensi dan Independensi Auditor pada Kualitas Audit Dimoderasi oleh Tekanan Klien. E-Jurnal Akuntansi Universitas Udayana, 11(1), 197-210.

Dinata, I. (2006). Standar Auditor Pemerintah. Yogyakarta: Andi Offset.

Furiady, O., \& Kurnia, R. (2015). The Effect of Work Experiences, Competency, Motivation, Accountability and Objectivity towards Audit Quality. Procedia - Social and Behavioral Sciences, 211, 328-335.

Halim, A., Sutrisno, Rosidi, \& Achsin, M. (2014). Effect of Competence and Auditor Independence on Audit Quality with Audit Time Budget and Professional Commitment as a Moderation Variable. International Journal of Business and Management Invention, 3(6), 64-74.

Hanjani, A., \& Rahardja, R. (2014). Pengaruh Etika Auditor, Pengalaman Auditor, Fee Audit, dan Motivasi Auditor Terhadap Kualitas Audit (Studi pada Auditor KAP di Semarang). Diponegoro Journal of Accounting, 3(2), 1-9.

Indonesia, D. P. (2008). Kamus Besar Bahasa Indonesia. Jakarta: Balai Pustaka.

Kertarajasa, A. Y., Marwa, T., \& Wahyudi, T. (2019). The Effect of Competence, Experience, Independence, Due Professional Care, And Auditor Integrity On Audit Qualitiy With Auditor Ethics As Moderating Variable. Journal of Accounting, Finance and Auditing Studies, 5(1), 80-99.
Kharismatuti, N., \& Hadiprajitno, P. B. (2012). Pengaruh Kompetensi dan Independensi Terhadap Kualitas Audit Dengan Etika Auditor Sebagai Variabel Moderasi (Studi empiris pada internal auditor BPKP DKI Jakarta). Diponegoro Journal of Accounting, 1(1), 1-10.

Kurnia, W., Khomsiyah, K., \& Sofie, S. (2014). Pengaruh Kompetensi, Independensi, Tekanan Waktu Dan Etika Auditor Terhadap Kualitas Audi. e-Journal Akuntansi Fakultas Ekonomi Universitas Trisaki, 1(2), 49-67.

Kusharyanti. (2003). Temuan Penelitian Mengenai Kualitas Audit Dan Kemungkinan Topik Penelitian Di Masa Datang. Jurnal Akuntansi Manajemen, Desember(2003), 25-60.

Kwanbo, L. M. (2009). Internal Control and the Issues of Independence \& Confidentiality in Nigerian Local Government Auditing: An Examination.

Lastanti, H. S. (2005). Tinjauan Terhadap Kompetensi dan Independensi Akuntan Publik : Refleksi Atas Skandal Keuangan. Media Riset Akuntansi. Media Riset Akuntansi, Auditing dan Informasi, 5(1), 85-97.

Libby, R., \& Luft, J. (1993). Determinants of judgment performance in accounting settings: Ability, knowledge, motivation, and environment. Accounting, Organizations and Society, 18(5), 425-450.

Lubis, H. (2009). Pengaruh keahlian, independensi, kecermatan profesional dan kepatuhan pada kode etik terhadap kualitas auditor pada Inspektorat Provinsi Sumatera Utara. Universitas Sumatera Utara.

Lufriansyah, L. (2017). Due professional care dalam memediasi pengaruh kompetensi, independensi, dan motivasi auditor terhadap kualitas audit. Jurnal Studi Akuntansi \& Keuangan, 1(1), 3952.

Made, T. N., \& Aryanto, D. (2016). Profesionalisme Sebagai Pemoderasi Pengaruh Independensi Pada Kinerja Auditor. E-Jurnal Akuntansi Universitas Udayana, 14(3), 1895-1923.

Mardiasmo. (2002). Akuntansi Sektor Publik. Yogyakarta: Andi Offset.

Maryani, T., \& Ludigdo, U. (2001). Survei atas faktorfaktor yang mempengaruhi sikap dan perilaku etis akuntan. Jurnal TEMA, 2(1), 49-62. 
Messier Jr., W. F., \& Quilliam, W. C. (1992). The Effect Of Accountability On Judgement Development Of Hypotesis For Auditing. Auditing: A Journal of Practice \& Theory, 11, 123-138.

Mulyadi. (2014). Auditing (6th ed.). Jakarta: Salemba Empat.

Munawir, S. (2014). Analisis Laporan Keuangan. Yogyakarta: Liberty.

Nasyiah, N., \& Payamta, P. (2002). Sikap Akuntan dan Pengguna Jasa Akuntan Publik Terhadap Advertensi Jasa Akuntan Publik. Jurnal Akuntansi dan Auditing Indonesia, 6(1), 43-61.

Ningsih, A. P. R. C., \& Yaniartha, P. D. (2013). Pengaruh Kompetensi, Independensi, Dan Time Budget Pressure Terhadap Kualitas Audit. EJurnal Akuntansi Universitas Udayana, 4(1), 92109.

Octavia, E., \& Widodo, N. R. (2015). The Effect of Competence and Independence Of Auditors on the Audit Quality. Research Journal of Finance and Accounting, 6(3), 189-194.

Okolie, A. O. (2013). Audit Quality and Accrual Based Earnings Management of Quoted Companies in Nigeria. IOSR Journal of Economics and Finance (IOSR-JEF), 2(2), 7-16.

Pandoyo. (2016). The Effect of Auditor Competence, Independen, Audit Experience, Organizational Culture and Leadership Against Auditor Profesionalism and Its Implication On Audit Quality. International Journal of Advanced Research (IJAR), 4(5), 1632-1646.

Pickett, K. H. S. (2005). The essential handbookof internal auditing. West Sussex: John Wiley \& Sons.

Pitaloka, Y., \& Widanaputra, A. A. G. . (2016). Integritas Auditor Sebagai Pemoderasi Pengaruh Kompetensi Dan Independensi Pada Kualitas Audit. E-Jurnal Akuntansi Universitas Udayana, 16(2), 1574-1603.

Prasetyo, E. B., \& Utama, I. M. K. (2015). Pengaruh Independensi, Etika Profesi, Pengalamang Kerja Dan Tingkat Pendidikan Auditor Pada Kualitas Audit. E-Jurnal Akuntansi Universitas Udayana, 11(1), 115-129.

Pritama, Y., Supriana, T., \& Torong, Z. B. (2017). The Factors of The Infuence on Audit Quality at The Inspectorate General of Ministry of Environment and Foresty. 1st Economics and Business International Conference 2017 (pp. 249-252).
Rahayu, T., \& Suryono, B. (2016). Pengaruh Independensi, Etika Auditor dan Pengalaman Auditor terhadap Kualitas Audit. Jurnal Ilmu dan Riset Akuntansi, 5(4).

Rahmina, L. Y., \& Agoes, S. (2014). Influence of Auditor Independence, Audit Tenure, and Audit Fee on Audit Quality of Members of Capital Market Accountant Forum in Indonesia. Procedia - Social and Behavioral Sciences, 164(August), 324-331. Elsevier B.V. Retrieved from

Ramadhanis, S. (2013). Pengaruh Kompetensi, Independensi dan Motivasi terhadap Kualitas Audit Pada Inspektorat. e-Jurnal Binar Akuntansi, 2(1).

Rialdy, N., Sari, M., \& Nainggolan, E. P. (2020). Model Pengukuran Kualitas Audit Internal (Studi Pada Auditor Internal Pada Perusahaan Swasta, BUMD dan BUMN di Kota Medan). Jurnal Samudra Ekonomi dan Bisnis, 11(2), 210-226.

Robbins, S. P., \& Judge, T. A. (2011). Organizational Behavior (14th ed.). New Jersey: Prentice Hall.

Saifudin, S. (2004). Pengaruh Kompetensi dan Independensi Terhadap Opini Audit Going Concern (Studi Kuasieksperimen pada Auditor dan Mahasiswa). Tesis Program Pasca Sarjana Magister Akuntansi Universitas Diponegoro.

Samsi, N., Riduwan, A., \& Suryono, B. (2013). Pengaruh Pengalaman Kerja, Independensi, dan Kompetensi Terhadap Kualitas Audit: Etika Auditor Sebagai Variabel Pemoderasi. Jurnal Ilmu dan Riset Akuntansi, 1(2), 206-226.

Saripudin, Herawaty, N., \& Rahayu. (2012). Pengaruh Independensi, Pengalaman, Due Professional Care, dan Akuntabilitas Terhadap Kualitas Audit (Survei Terhadap Auditor KAP di Jambi dan Palembang). E-Jurnal Binar Akuntansi, 1(1), 413.

Sukriah, I., Akram, \& Inapty, B. A. (2009). Pengaruh Pengalaman Kerja, Independensi, Obyektifitas, Integritas dan Kompetensi Terhadap Kualitas Hasil Pemeriksaan. Simposium Nasional Akuntansi XII (pp. 1-10).

Tetlock, P. E., \& Kim, J. I. (1987). Accountability and judgment processes in a personality prediction task. Journal of Personality and Social Psychology, 52(4), 700-709.

Tjun, L. T., Marpaung, E. I., \& Setiawan, S. (2012). Pengaruh Kompetensi dan Independensi Auditor Terhadap Kualitas Audit. Jurnal Akuntansi, 4(1), $33-56$. 
Jurnal Akuntansi dan Pajak, 21 (02), 2021, 442

Triarini, D. A. W., \& Latrini, M. Y. (2016). Pengaruh Kompetensi, Skeptisme Profesional, Motivasi, dan Disiplin Terhadap Kualitas Audit Kantor Inspektorat Kabupaten/Kota di Bali. E-Jurnal

Zahmatkesh, S., \& Rezazadeh, J. (2017). The effect of Akuntansi Universitas Udayana, 14(2), 10921119.

Usman, A., Sudarma, M., Habbe, H., \& Said, D. (2014). Effect of Competence Factor, Independence and Attitude against Professional Auditor Audit Quality Improve Performance in Inspectorate (Inspectorate Empirical Study in South Sulawesi Province). IOSR Journal of Business and Management (IOSR-JBM), 16(1), 1-13. 